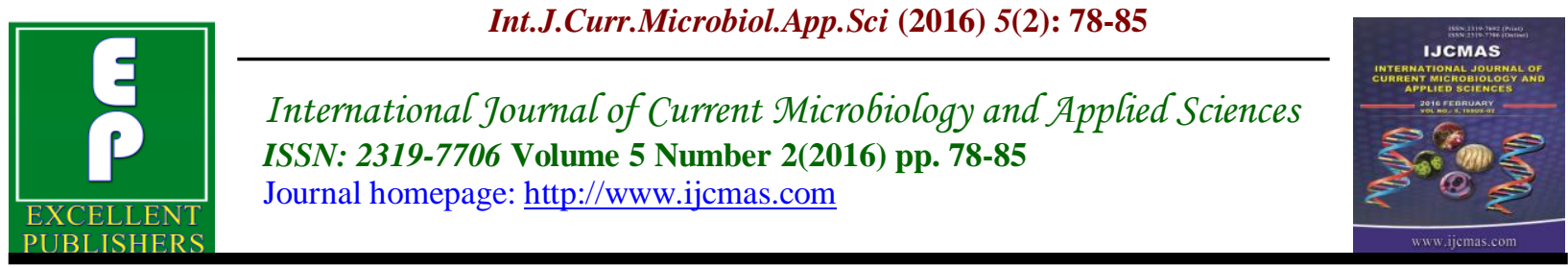

Original Research Article

doi: http://dx.doi.org/10.20546/ijcmas.2016.502.008

\title{
Prevalence and Antimicrobial Susceptibility Patterns of Aerobic Bacterial Isolates from Pyogenic Wound Infections at a Tertiary Care Institute in Haryana, India
}

\author{
Jyoti Sangwan $^{1 *}$, Pooja Singla ${ }^{1}$, Pratibha Mane ${ }^{1}$, Sumit Lathwal ${ }^{2}$ and A. K. Malik ${ }^{1}$ \\ ${ }^{1}$ Department of Microbiology, SHKM, GMC, Nalhar, Mewat, Haryana, India \\ *Corresponding author
}

\begin{abstract}
A B S T R A C T
Keywords

Wound Infection, Inflammation, Antimicrobial resistance, Staphylococcus aureus,

Pseudomonas, Culture and Sensitivity

\section{Article Info}

Accepted: 09 January 2016 Available Online: 10, February 2016

Wound infection is one of the health problems that is caused and aggravated by the invasion of pathogenic organisms. Information on local pathogens and sensitivity to antimicrobial agent is crucial for successful treatment of wounds. So the present study was conducted to determine antimicrobial susceptibility pattern of bacterial isolates from wound infection and their sensitivity to antimicrobial agents. The study was carried out from Jan 2015 to July 2015 in a tertiary care centre located in remote settings of Mewat. Wound swabs and pus samples were processed in the diagnostic microbiology laboratory immediately on reception following standard guidelines. The antibiotic sensitivity testing of all isolates was performed by Kirby Bauer's disc diffusion method and interpreted as per CLSI guidelines. Analysis of 438 pus samples showed $72.6 \%$ culture positivity with Surgical wards (39.7\%) being the major contributor. Out of positive samples $82.3 \%$ were mono microbial and $17.7 \%$ poly microbial. Staphylococcus aureus (24.2\%) was the most common organisms followed by, Pseudomonas (21.4\%), E coli (14.8\%), Proteus spp (8.8\%), Citrobacter spp (8.2\%), Enterococcus (6.6\%), Klebsiella spp (6.1\%) and Streptococcus $(2.2 \%)$. Incidence of MRSA was $48.9 \%$ and $42.8 \%$ respectively. ESBL among Enterobactericeae were noted. Percentage resistance of isolates to individual antibiotic was also noted. The changing trends of antimicrobial susceptibility in bacterial isolates from pus can serve as a useful tool for physicians to start empirical treatment of patients at the earliest according to the geographical areas and emerging multi-resistant bacteria.
\end{abstract}

\section{Introduction}

Pyogenic infection is characterized by several local inflammation, usually with pus formation, generally caused by one of the pyogenic bacteria, which can produce the accumulation of dead leukocytes and infectious agent commonly known as pus. Pyogenic infections may be endogenous or exogenous .
A break or abrasion in the skin can provide an entryway for these surface bacteria into the body, and they stick very well to the moist edges of a cut. The bacteria begin to multiply and extend into the cut. The body's defense mechanism includes bringing immune cells into the area to fight against the bacteria. Eventually, accumulation of 
these cells produces the thick whitish liquid that we call pus (Koneman et al., 2005)

The inadvertent use of antibiotics leads to emergence of drug resistant pathogens, which in turn acts as a great challenge to the health services. Moreover, highly virulent strains and capacity to adapt quickly to changing environment worsens the situation and is a matter of concern (Sowmya $\mathrm{N}$ et al., 2014). Skin and soft tissue infections that usually follow minor traumatic events or surgical procedures are caused by a wide spectrum of bacteria. Involvement of antibiotic resistant organisms in these infections increases the difficulty of their treatment and may have significant influence on the ultimate outcome.

Various studies across the globe have been consistent enough to show a predictable bacterial profile in the pyogenic wound infections. This makes an important observation for a clinician who intends to start empirical treatment to his patients, while laboratory culture reports are awaited. The present study was designed to evaluate the profile of aerobic pyogenic bacteria along with their susceptibility to antimicrobial agents in our region.

\section{Materials and Methods}

This prospective study was carried out in Department of Microbiology from January 2015 to July 2015. A total number of 438 pus samples were obtained for aerobic culture and sensitivity from different IPDs \& OPDs of our hospital.

Pus samples were collected with sterile disposable cotton swabs and aspirates in syringe and were transported and processed in the microbiology laboratory immediately. They were inoculated on to Blood agar (BA), Mac Conkey agar (MA) and Nutrient agar (NA). Culture plates were incubated at $37^{\circ} \mathrm{C}$ for $24 \mathrm{hrs}$ to $48 \mathrm{hrs}$ in aerobic condition. After incubation, identification of bacteria from positive cultures was done using standard phenotypic methods. Simultaneously, a Gram stain was also performed on direct samples in which presence of pus cells and bacteria if present were noted. Also clinical details of patients were noted.

The antibiotic sensitivity testing of all isolates was performed by Kirby Bauer's disc diffusion method on Muller Hinton agar and interpreted as per CLSI guidelines and classified as sensitive and resistant (NCCLS. 2002.). Standard antibiotics ampicillin $(30 \mu \mathrm{g})$, amoxyclav $(30 \mu \mathrm{g})$, cefotaxime $(30 \mu \mathrm{g})$, ceftazidime $(30 \mu \mathrm{g})$, gentamicin $(10 \mu \mathrm{g}$ and $120 \mu \mathrm{g})$, imipenem $(10 \mu \mathrm{g})$, cefoxitin $(30 \mu \mathrm{g})$, linezolid $(30 \mu \mathrm{g})$, vancomycin $(30 \mu \mathrm{g})$, piperacillin $(100 \mu \mathrm{g})$, Ciprofloxacin $(5 \mu \mathrm{g})$, Erythromycin $(10 \mu \mathrm{g})$, Netilmicin $(30 \mu \mathrm{g})$, Colistin, Teicoplanin(30 $\mu \mathrm{g})$, Amikacin (30 $\mu \mathrm{g})$, Piperacillin Tazobactam $(100 / 10 \mu \mathrm{g}), \quad$ Tigecyclin, Polymyxin B(10 $\mu \mathrm{g})$ Clindamycin $(2 \mu \mathrm{g})$, Cotrimoxazole (Trimethoprim1.25 $\mu \mathrm{g}$ / Sulfomethoxazole $23.75 \mu \mathrm{g}$ ) were tested. Escherichia coli ATCC 25922, Pseudomonas aeruginosa ATCC 27853 and Staphylococcus aureus ATCC 25923 were used for quality control. All the culture media, biochemical media and antibiotics used were obtained from Hi Media.

Detection of Methicillin resistant Staphylococcus aureus (MRSA) was done with Cefoxitin $(30 \mu \mathrm{g})$ disc. Extended spectrum betalactamase (ESBL) production was detected with the help of Ceftazidime $(30 \mu \mathrm{g})$ and Ceftazidime + Clavulanic acid $(30 / 10 \mu \mathrm{g})$. Results obtained were analyzed by counts and percentages using MS Excel, 2007 version. 


\section{Results and Discussion}

A total of 438 samples were received during the study period out of which $318(72.6 \%)$ were culture positive. Among these 262(82.4\%) were monomicrobial i.e only one isolate obtained and 56(17.6\%) were polymicrobial i.e culture yielded more than one isolate. The department-wise distribution showed that surgery $(39.7 \%)$ department was the major contributor of pus samples followed by ENT (19.6\%), orthopedics (18.3\%), OBG (8.8\%), ICUs $(5.9 \%)$ and others $(7.7 \%)$.The various bacterial isolates from different departments is shown in Figure 1.

A total of 364 organisms were isolated. The commonest organism were family Enterobacteriaceae $(38.5 \%)$ followed by Staphylococcus spp (26.9\%), Pseudomonas (21.4\%), Enterococcus (6.6\%), Diphtheroids (3.8\%), Streptococcus pyogens (2.2\%) and Acinetobacter (0.5\%) as shown in Figure 2.

The most predominant gram positive bacteria $\quad(\mathrm{n}=144) \quad$ isolated was Staphylococcus aureus $(61.1 \%)$ followed by Enterococci (16.7 \%),CONS (6.9\%), Streptococcus pyogens (5.6\%) and Diphtheroids (1.4\%). Though Enterobacteriaceae was the most predominant family isolated, Pseudomonas (35.5\%) was the most predominant single Gram negative organism( $\mathrm{n}=220)$. Enterobacteriaceae $\quad(n=140)$ mainly comprised of E.coli (38.6\%) followed by Proteus (22.8\%), Citrobacter (21.4\%), Klebsiella (15.7\%) and Morganella (1.4\%) as depicted in Figure 3.

Sensitivity of Gram positive bacteria were tested as per CLSI guidelines against Amoxycillin, Amoxy Clav, Cotrimoxazole, Ciprofloxacin, Erythromycin, Clindamycin, Gentamicin, Amikacin, Vancomycin,
Linezolid and Teicoplanin. Sensitivity pattern of Gram positive isolates is shown in Table1. Similarly Gram negative bacteria of family Enterobacteriaceae were tested as per CLSI guidelines against Ampicillin, Cefotaxime, Ceftazidime, Amikacin, Gentamicin, Imipenem, Ciprofloxacin, Colistin, Tigecyclin, Polymyxin B. Sensitivity pattern of family Enterobacteriaceae is shown in Table 2. Pseudomonas and Acinetobacter spp were tested against Ceftazidime, Amikacin, Gentamicin, Piperacillin, Netilmicin Piperacillin Tazobactam combination, Ciprofloxacin, Imipenem, Colistin, Tigecyclin and Polymyxin B as per CLSI guidelines. Their sensitivity pattern are shown in Table 3.Sensitivity pattern of Family Enterobactericeae and Pseudomonas and Acinetobacter is shown in Table 2 and Table 3 respectively.

MRSA was detected with the help of Cefoxitin $(30 \mu \mathrm{g})$ and $43(48.9 \%)$ were found to be MRSA. ESBL producers among Escherichia coli, Klebsiella pneumoniae and Proteus mirabilis was detected with ceftazidime $\left(\begin{array}{ll}30 & \mu \mathrm{g}\end{array}\right)$ and ceftazidime clavulanic acid $(30 / 10 \mu \mathrm{g})$ disc and was found to be 18 (33.3\%), 9 (40.9.1\%) and 9 (28.1\%) respectively.

Despite advances in the operative techniques and better understanding of the pathogenesis of wound infection, postoperative wound infection continues to be a major source of morbidity and mortality for patients undergoing operative procedures. Wound is a major concern among healthcare practitioners, not only in terms of increased trauma to the patient but also in view of its burden on financial resources and the increasing requirement for cost effective management within the health care, system (Bowler et al., 2001). Its rate varies in different countries, different areas and even 
in different hospitals. In present study, rate of wound infection was high, being $72.6 \%$. Similar trends were reported by other studies conducted in India (Suchitra et al., 2009) and (Manikandan et al., 2013)

Though family Enterobacteriaceae was the most predominant group in our study, it was Staphylococcus aureus which was the predominant organism isolated and constituted $24.2 \%$ of the isolates. This was consistent with other similar studies (Swati Duggal et al., 2015), (Tiwari et al .2010) and (Lee C Y et al., 2009). Pseudomonas $(29.73 \%)$ is the most common gram negative bacterial isolate which is in accordance with the report of (Basu et al., 2009). Surgical ward had given maximum number of pus samples followed by Orthopedic and ENT department.

The high prevalence of $\mathrm{S}$. aureus infection may be because it is an endogenous source of infection. Infection with this organism may also be due to contamination from the environment e.g. contamination of surgical instruments. With the disruption of natural skin barrier $S$. aureus, which is a common bacterium on surfaces, easily find their way into wounds.

Table.1 Sensitivity Pattern of Gram Positive Isolates

\begin{tabular}{|l|l|l|l|}
\hline Antibiotic & $\begin{array}{l}\text { Staphylococcus spp } \\
(\mathrm{N}=98)\end{array}$ & $\begin{array}{l}\text { Enterococcus spp } \\
(\mathrm{N}=24)\end{array}$ & $\begin{array}{l}\text { Streptococcus pyogens } \\
(\mathrm{N}=8)\end{array}$ \\
\hline Amoxycillin & $10(10.2)$ & $6(25.0)$ & $8(100)$ \\
\hline Amoxy Clav & $21(21.4)$ & $6(25.0)$ & $8(100)$ \\
\hline Cotrimoxazole & $20(20.4)$ & $6(25.0)$ & $8(100)$ \\
\hline Cefoxitin & $45(46.0)$ & - & - \\
\hline Erythromycin & $64(65.3)$ & $5(20.8)$ & $8(100)$ \\
\hline Gentamicin & $70(71.4)$ & - & - \\
\hline Amikacin & $75(76.5)$ & - & - \\
\hline Ciprofloxacin & $22(22.4)$ & - & $8(100)$ \\
\hline Clindamycin & $74(75.5)$ & $8(33.3)$ & $8(100)$ \\
\hline Gentamicin 120 & - & $21(87.5)$ & - \\
\hline Vancomycin & $98(100)$ & $24(100)$ & - \\
\hline Linezolid & $98(100)$ & $24(100)$ & - \\
\hline Teicoplanin & $98(100)$ & $24(100)$ & - \\
\hline
\end{tabular}

*Number in Parenthesis denotes Percentage

Figure.1 Department Wise Distribution of Bacterial Isolates

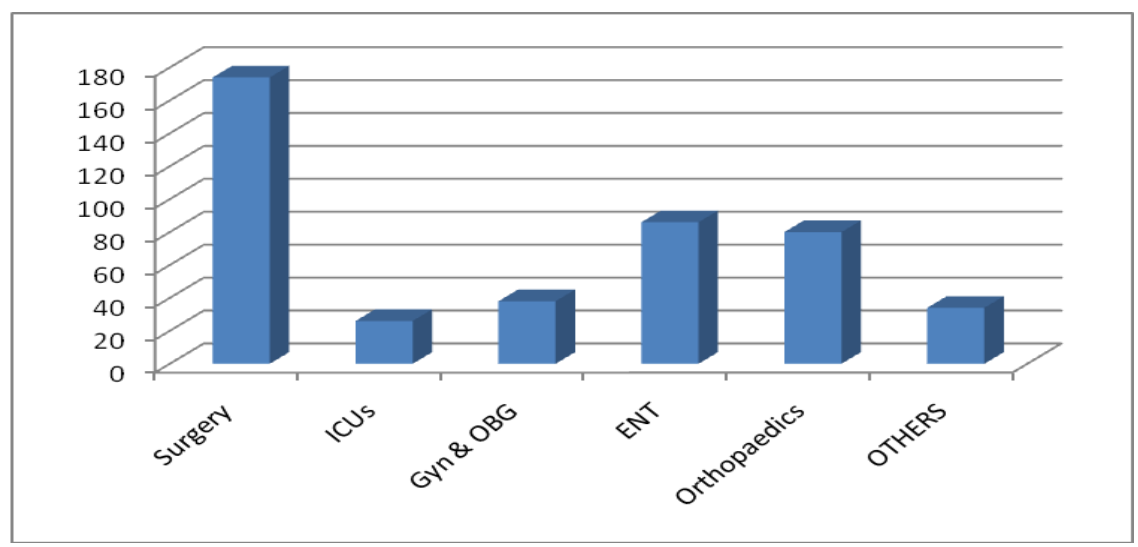


Table.2 Sensitivity Pattern of Enterobacteriaceae Isolates

\begin{tabular}{|c|c|c|c|c|c|}
\hline Antibiotic & $\begin{array}{c}\text { E.coli } \\
(\mathrm{N}=54)\end{array}$ & $\begin{array}{c}\text { Klebsiella } \\
(\mathrm{N}=22)\end{array}$ & $\begin{array}{c}\text { Citrobacter } \\
(\mathrm{N}=30)\end{array}$ & $\begin{array}{c}\text { Proteus } \\
(\mathrm{N}=32)\end{array}$ & $\begin{array}{c}\text { Morganella } \\
(\mathrm{N}=2)\end{array}$ \\
\hline Ampicillin & $5(9.3)$ & $2(9.1)$ & $4(13.3)$ & $0(0)$ & $0(0)$ \\
\hline Cefotaxime & $27(50)$ & $11(50.0)$ & $19(63.3)$ & $32(100)$ & $2(100)$ \\
\hline Ceftazidime & $41(75.9)$ & $14(63.6)$ & $23(76.7)$ & $28(87.5)$ & $1(50)$ \\
\hline Cefepime & $42(77.8)$ & $19(86.4)$ & $21(70.0)$ & $21(65.6)$ & $2(100)$ \\
\hline Gentamicin & $29(53.7)$ & $12(54.5)$ & $20(66.7)$ & $18(56.2)$ & $1(50)$ \\
\hline Amikacin & $19(35.2)$ & $13(59.1)$ & $17(56.7)$ & $14(43.7)$ & $1(50)$ \\
\hline Ciprofloxacin & $6(11.1)$ & $1(4.5)$ & $10(33.3)$ & $5(15.6)$ & $2(100)$ \\
\hline Piperacillin & - & - & - & - & - \\
\hline Netilmicin & - & - & - & - & - \\
\hline Piperacillin + & & & & & - \\
tazobactam & - & - & - & - & $2(100)$ \\
\hline Imipenem & $54(100)$ & $20(90.9)$ & $30(100)$ & $32(100)$ & $2(100)$ \\
\hline Polymyxin B & $54(100)$ & $22(100)$ & $30(100)$ & $32(100)$ & $2(100)$ \\
\hline Tigecyclin & $50(92.6)$ & $15(68.2)$ & $29(96.7)$ & $32(100)$ & $2(100)$ \\
\hline Colistin & $54(100)$ & $22(100)$ & $30(100)$ & $32(100)$ & \\
\hline
\end{tabular}

*Number in Parenthesis denotes Percentage

Table.3 Sensitivity Pattern of Pseudomonas and Acinetobacter spp

\begin{tabular}{|c|c|c|}
\hline Antibiotic & $\begin{array}{c}\text { Pseudomonas } \\
(\mathrm{N}=78)\end{array}$ & $\begin{array}{c}\text { Acinetobacter } \\
(\mathrm{N}=2)\end{array}$ \\
\hline Ampicillin & - & $0(0)$ \\
\hline Cefotaxime & - & $1(50.0)$ \\
\hline Ceftazidime & $61(78.2)$ & $1(50.0)$ \\
\hline Cefepime & - & - \\
\hline Gentamicin & $51(65.4)$ & $1(50.0)$ \\
\hline Amikacin & $41(52.6)$ & $1(50.0)$ \\
\hline Ciprofloxacin & $18(23.1)$ & $0(0)$ \\
\hline Piperacillin & $5(6.4)$ & - \\
\hline Netilmicin & $1(1.3)$ & - \\
\hline $\begin{array}{c}\text { Piperacillin + } \\
\text { tazobactam }\end{array}$ & $26(33.3)$ & - \\
\hline Imipenem & $78(100)$ & $32(100)$ \\
\hline Polymyxin B & $78(100)$ & - \\
\hline Tigecyclin & - & $0(0)$ \\
\hline Colistin & $78(100)$ & $2(100)$ \\
\hline
\end{tabular}

*Number in Parenthesis denotes Percentage. 
Figure.2 Percentage Distribution of Organisms Isolated

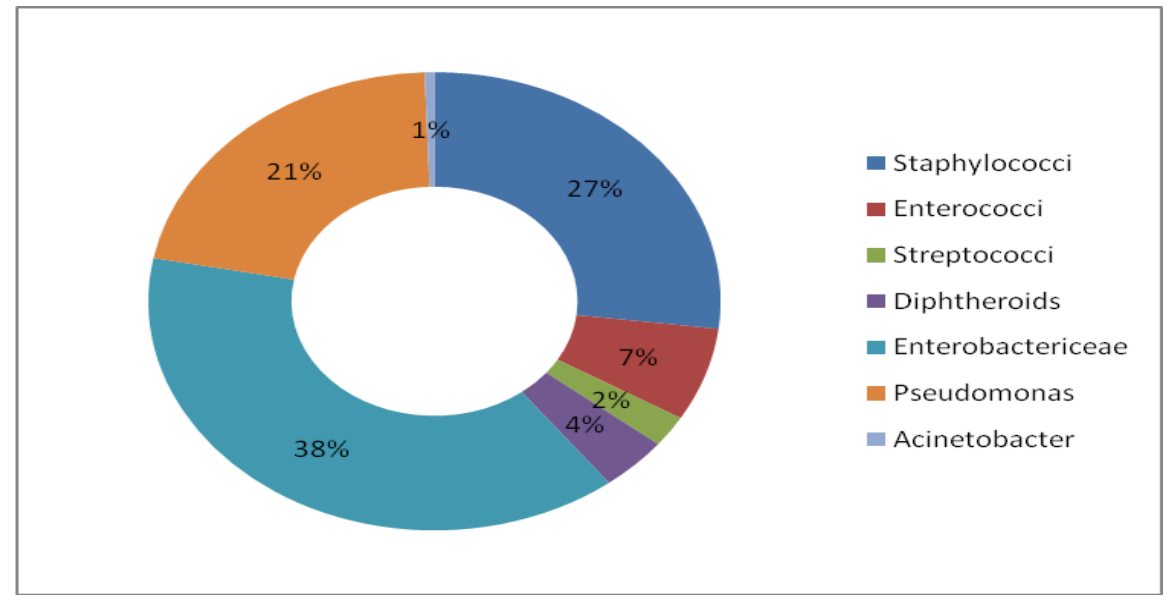

Figure.3 Distribution of Family Enterobacteriaceae

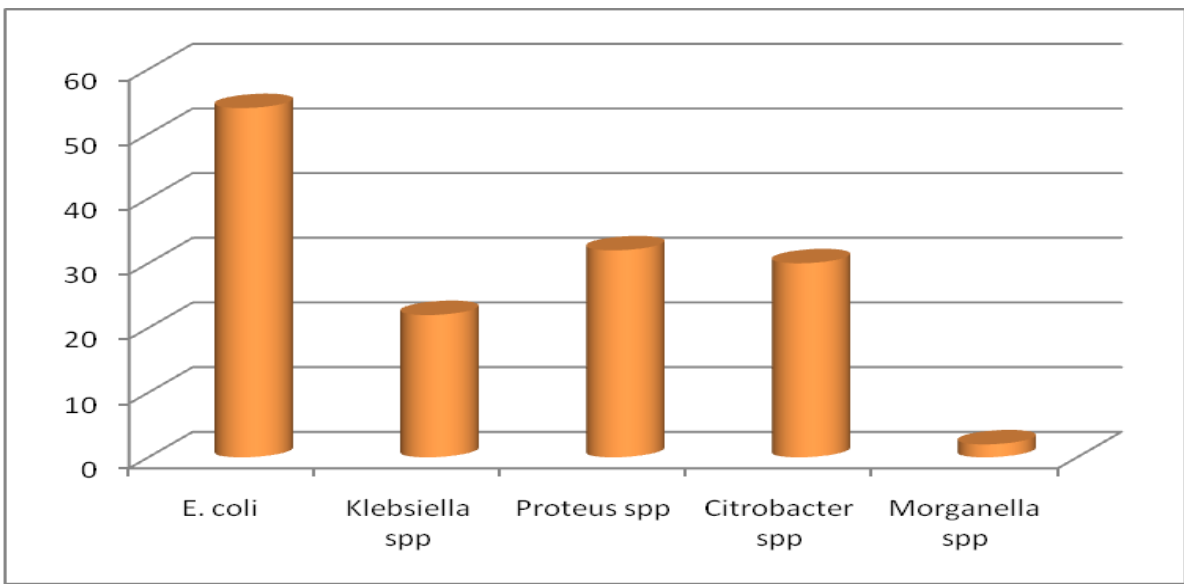

The antibiogram of gram positive cocci revealed that resistance to Vancomycin, Linezolid and Teicoplanin is yet to be seen in our set up. (Samra et al., 2009) also have reported the same. S. aureus shows very high resistance to Amoxycillin, Amoxy Clav, Cotrimoxazole and Ciprofloxacin (sensitivity ranging from 10-30\%).S. aureus was fairly sensitive to Amino glycoside group (sensitivity ranging from $70-75 \%$ ). Also S.aureus was also sensitive to Macrolide group (sensitivity 60-70\%). Enterococcus was highly resistant to Penicillins, Cotrimoxazole and Macrolides (sensitivity ranging from 20-30\%). Senitivity to Gentamicin was good in
Enterococcus (87.5\%) and also no resistance reported in Enterococcus isolated from wound infection. Streptococcus pyogens was sensitive to all the drugs tested in our set up.

Gram negative bacteria of Enterobacteriaceae were most susceptible to Imipenem (sensitivity 90-100\%), only two isolates of Klebsiella spp showed resistance. Enterobacteriaceae showed very high resistance to Ampicillin, Amoxy Clav and Ciprofloxacin (sensitivity ranging from 5$30 \%$ ). Resistance to Cephalosporins ranged from no resistance to resistance in 50\% isolates, where in E.coli and Klebsiella spp were the main contributors followed by 
Proteus, Citrobacter and no resistance in Morganella spp. This finds concordance with (Balan et al., 2013).Sensitivity to polymixin B and Colistin was $100 \%$ as all Enterobacteriaceae was sensitive. Sensitivity to Tigecyclin ranged from 68-100\%, Klebsiella showing highest resistance as seven isolates were resistant.

No resistance against Imipenem, Polymixin B and Colistin was reported in Pseudomonas and Acinetobacter spp isolated from wounds (Table 3). Piperacillin and Netilmicin are no more effective against Pseudomonas as sensitivity is only 1-6\%, Piperacillin Tazobactam combination being slightly better (sensitivity being $33.3 \%$ ). Sensitivity to Amikacin and Gentamicin is still there in Pseudomonas being 52.6 and $65.4 \%$ respectively. Sensitivity to Ceftazidime is also good in our set up being $78 \%$. This pattern of sensitivity of Pseudomonas and Acinetobacter spp has also been shown by (N.Sowmya et al., 2014) and (HV Prashanth et al., 2013). Acinetobacter is also still sensitive to Aminoglycosides and Ceftazidime whereas Tigecyclin has lost its effectiveness against Acinetobacter spp in our set up as none of the two isolate was sensitive to this drug.

In conclusion, Knowledge of the causative agents of wound infection in a specific geographic region is useful in the selection of antimicrobials for empiric therapy. As $S$. aureus was the most common organism isolated, it suggests that good hygine practices by the patient,their attendants and the health care providers is very crucial. Also fairly high rate of isolating Pseudomona spp needs attention. The susceptibility data suggests that multidrug resistance is not a severe problem in local area yet as we are a new set up. But rational use of antibiotics should be practiced to avoid emergence of multi drug resistant strains. The in vivo susceptibility of the antimicrobials agents correlates well with the in vitro susceptibility reports and in our majority of the patients achieved a good therapeutic response.

Also the pathogen shows susceptibility to certain older drugs suggesting a cyclical wave pattern of susceptibility to antimicrobial agents. We recommend drug holidays for the group of drugs which have become ineffective over a period of time and bringing in the agents to which the organisms are sensitive. A changing trend in antibiotic sensitivity profile of the isolates need to be monitored as there is limited availability of newer drugs and the emergence of resistant bacteria far exceeds the rate of new drug development.

\section{References}

Balan K, Sujitha K, Vijayalakshmi TS. Antibiotic susceptibility pattern of gram negative clinical Isolates in a Teaching Tertiary Care hospital. Scholars Journal of Applied Medical Sciences 2013; 1(2): 76-79.

Basu S, Ramchuran Panray T, Bali Singh T, Gulati AK, Shukla VK. A ; prospective, descriptive study to identify the microbiological profile of chronic wounds in outpatients. OstomyWound Manage. 2009 Jan; 5(1):14-20.

Bowler, C., O.C. Chigbu and Giacometti, H. Emergence of Antimicrobial Resistance Bacteria. J. Antimicr and Chemotherapy. 2001;23:12 23.

Manikandan, C., and A. Amsath. Antibiotic susceptibility of bacterial strains isolated fromwound infection patients in Pattukkottai, Tamilnadu, India. Int.J.Curr.Microbiol.App.Sci.2013; 2(6): 195-203. 
HV Prashanth, R Prakash, RJ Girishbabu, A Kausar, V Krishnamurthy, J Pharm Biomed Sci, 2013, April; 29 (29): 816819.

Koneman, W.K., Allen, S. D., Janda, W.M., Schreckenberger, P.C., Propcop, G.W., Woods, G.L. and Winn, W.C., Jr. Philadelphia Color Atlas and Textbook of Diagnostic Microbiology, 6th ed. Lippincott-Raven Publisher, 2005, pp: 624-662.

Lee CY, Chen PY, Huang FL, Lin F. icrobiologic spectrum and susceptibility pattern of clinical isolates from the pediatric intensive care unit in ingle medical center -6 years' experience. J Microbiol Immunol Infect. 2009 Apr; 42(2):1605.

NCCLS. 2002. Performance standards for antimicrobial susceptibility testing: Twelfth informational supplement M100-S12. NCCLS, Wayne, PA, USA.

Samra Z, Ofer O, Shmuely H. Susceptibility of methicillin-resistant Staphylococcus aureus to vancomycin, teicoplanin, linezolid, pristinamycin and other antibiotics. The Israel Medical Association Journal March 2005; 7(3): 148-150.

Sowmya N, Savitha S, Mallure S, Mohanakrishnan K, Sumathi G, Arumugam P. A two year study of spectrum of bacterial isolates from wound infections by aerobic culture and their antibiotic pattern in a tertiary care center. International Journal of Current Microbiology and applied science 2014; 3(8):292-295.

Suchitra, J.B. and Lakshmidevi N. Surgical site infections. Assessing risk factors and antimicrobial sensitivity patterns. Afr. J. Microbiol. Res. 2009; 3:185-9.

Swati Duggal, P K Khatri, R S Parihar, Rajat Arora. Antibiogram of Various Bacterial Isolates from Pus Samples in a Tertiary Care Centre in Rajasthan. International Journal of Science and Research, 2015; 4(5):1580-84.

Tiwari P, Kaur S. Profile and sensitivity pattern of bacteria isolated from various cultures in a Tertiary Care ospital in Delhi. Indian J Public Health. 2010 Oct-Dec; 54(4):213-5.

\section{How to cite this article:}

Jyoti Sangwan, Pooja Singla, Pratibha Mane, Sumit Lathwal and A. K. Malik. 2016. Prevalence and Antimicrobial Susceptibility Patterns of Aerobic Bacterial Isolates from Pyogenic Wound Infections at a Tertiary Care Institute in Haryana, India. Int.J.Curr.Microbiol.App.Sci. 5(2):78-85. doi: http://dx.doi.org/10.20546/ijcmas.2016.502.008 